Tohoku J. Exp. Med., 2006, 208, 275-281

Case Report

\title{
Chondrosarcoma of the Ring Finger: A Case Report and Review of the Literature
}

\author{
Masahito Hatori, Mika Watanabe, ${ }^{1}$ Hideyoshi Kotake ${ }^{2}$ and Shoichi Kokubun \\ Department of Orthopaedic Surgery, ${ }^{I}$ Department of Pathology, Tohoku \\ University Graduate School of Medicine, Sendai, Japan, and \\ ${ }^{2}$ Department of Orthopaedic Surgery, Kurihara City Wakayanagi Hospital, \\ Kurihara, Japan
}

Hatori, M., Watanabe, M., Kotake, H. and Kokubun, S. Chondrosarcoma of the Ring Finger: A Case Report and Review of the Literature. Tohoku J. Exp. Med., 2006, 208 (3), 275-281 — Enchondromas are the most common benign cartilaginous bone tumors arising in the medullary cavity of the small bones of the hand. In contrast, chondrosarcomas, commonly occurring in the pelvis and proximal femur and humerus, are very uncommon at this site. We report an unusual case of chondrosarcoma arising in the ring finger proximal phalanx with its radiological and histological features and reviewed the literature. The patient was an 80-year-old man whose chief complaint was swelling and pain for seven years. The findings of cortical irregular thickening by plain radiography and computed tomography and soft tissue extension by magnetic resonance imaging suggested the tumor was chondrosarcoma rather than a common enchondroma. Thorough curettage and artificial bone grafting was performed because of the age of the patient, his senile dementia and the strong desire of the patient and his family. Histological examination revealed that the tumor was composed of polygonal cells with eosinophilic cytoplasm proliferating in the chondromatous matrix with partially myxoid changes. Nuclear irregularity, binucleated cells, bone permeation and encasement were observed and the tumor was diagnosed as grade 2 chondrosarcoma. The tumor recurred five months after surgery. Amputation of the ring finger including the distal part of the 4th metacarpal was performed. At two years after surgery, the patient was free from recurrence or lung metastasis. In conclusion, details of radiological as well as pathological findings are essential for differential diagnosis between benign enchondroma and chondrosarcoma in the hand. Chondrosarcoma of the hand requires a prompt and more radical treatment than enchondroma. Wide excision is recommended to avoid local recurrence or metastasis.

enchondroma; chondrosarcoma; phalanx; hand

(C) 2006 Tohoku University Medical Press

Enchondroma is a benign, intramedullary cartilage tumor that is usually found in the bones of the hands (Rieger et al. 2000). In contrast, chondrosarcoma, a malignant tumor with hyaline cartilage differentiation, most commonly occurs in the bones of the pelvis followed by the proxi-

Received November 24, 2005; revision accepted for publication January 10, 2006.

Correspondence: Masahito Hatori, M.D., Department of Orthopaedic Surgery, Tohoku University School of Medicine, 1-1 Seiryomachi, Aoba-ku, Sendai 980-8574, Japan.

e-mail: mhato@mail.tains.tohoku.ac.jp 
mal femur, proximal humerus, distal femur and ribs (Bertoni et al. 2002). It is very uncommon in the hand (Kuur et al. 1989; Bovee et al. 1999; Essadki et al. 2001). We report an unusual case of chondrosarcoma arising in the ring finger proximal phalanx with its radiological and histological features and reviewed the literature.

\section{Case Report}

The patient was an 80-year-old man. He noticed swelling and pain in his right ring finger 7 years previously. One year before, the swelling, pain and restriction of his ring finger worsened. At the initial examination, there was redness and swelling of his right ring finger (Fig. 1). The range of motion of this finger was slightly restricted. Plain radiography (Fig. 2) and computed tomography (CT) (Fig. 3) showed a lesion with punctate calcification suggestive of chondroid matrix mineralization, endosteal scalloping and irregular cortical thickening with subtle periosteal reaction in the proximal phalanx of the left ring finger. Magnetic resonance imaging clearly

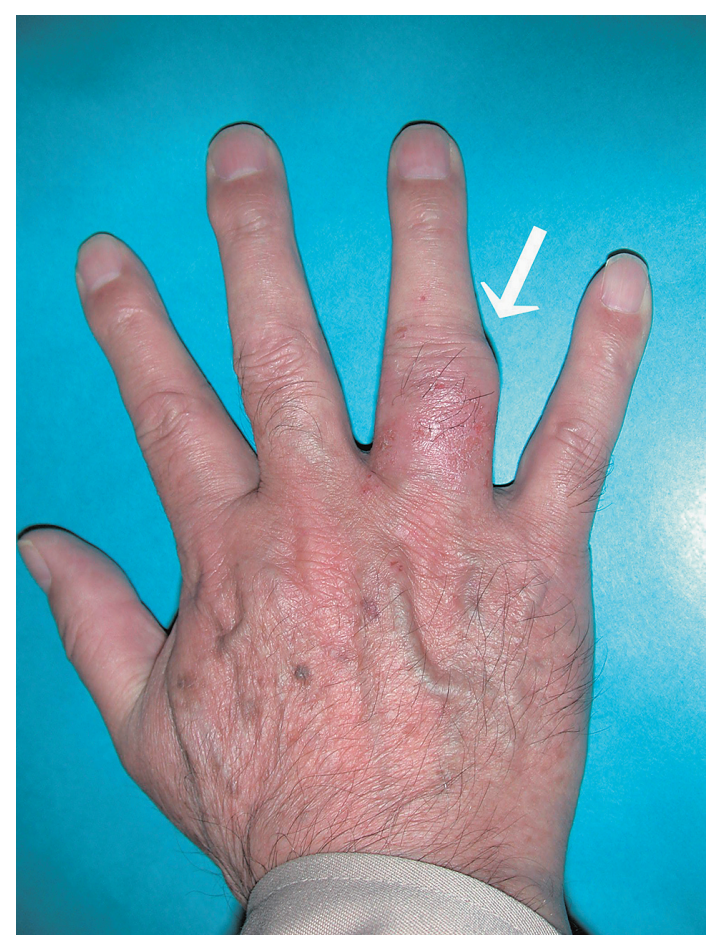

Fig. 1. Photograph showing swelling (arrow) of the ring finger.

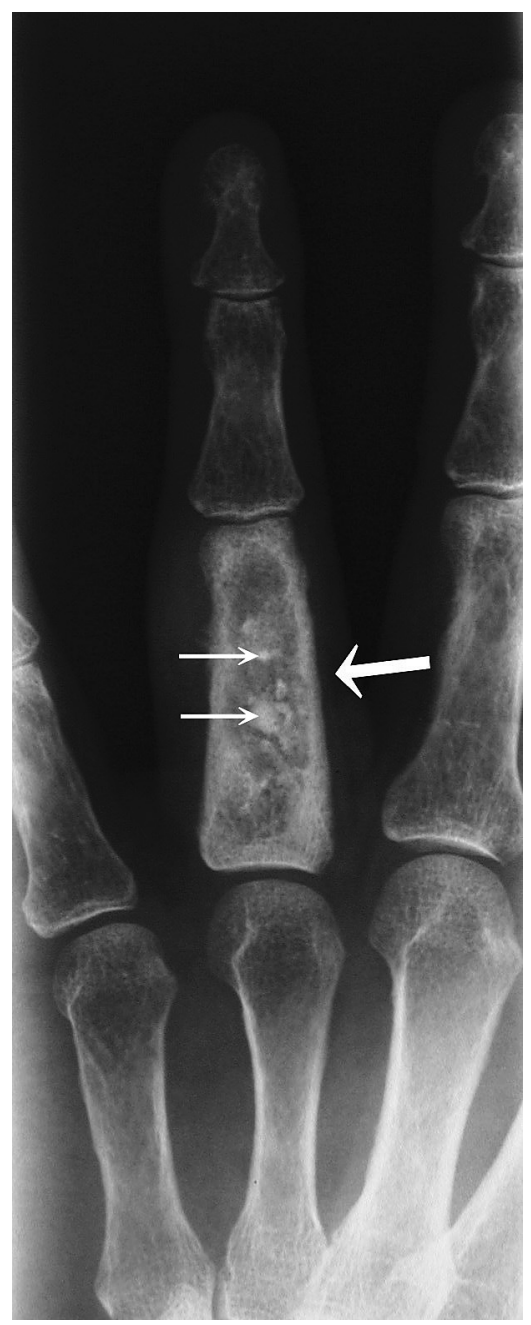

Fig. 2. Plain radiograph showing a lesion with punctate calcification (short arrows) and irregular thickening of the cortex (large arrow) in the proximal phalanx of the ring finger.

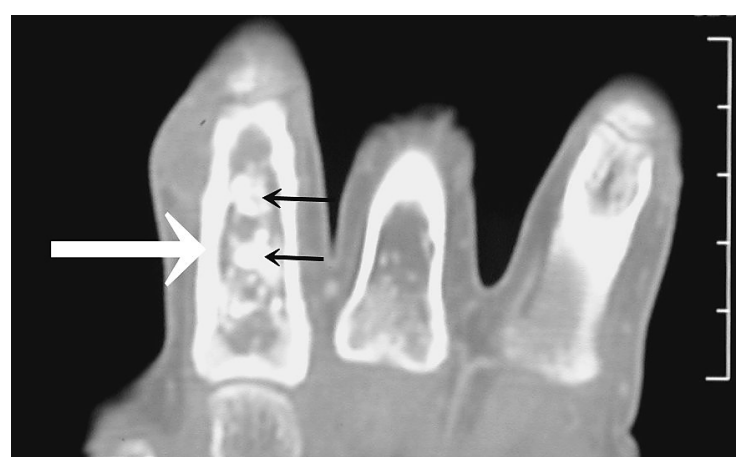

Fig. 3. Computed tomograph clearly demonstrating a lesion with irregular thickening of the cortex (large arrow) and punctate calcification (short arrows). 
showed extraskeletal extension of the tumor. The mass had iso-signal intensities on T1 weighted images, high signal intensities on $\mathrm{T} 2$ weighted images and enhancement of mainly the peripheral area after gadolinium injection. Multiple lines with high signal intensities in the cortex were observed suggesting bone permeation (Figs. 4A,

A

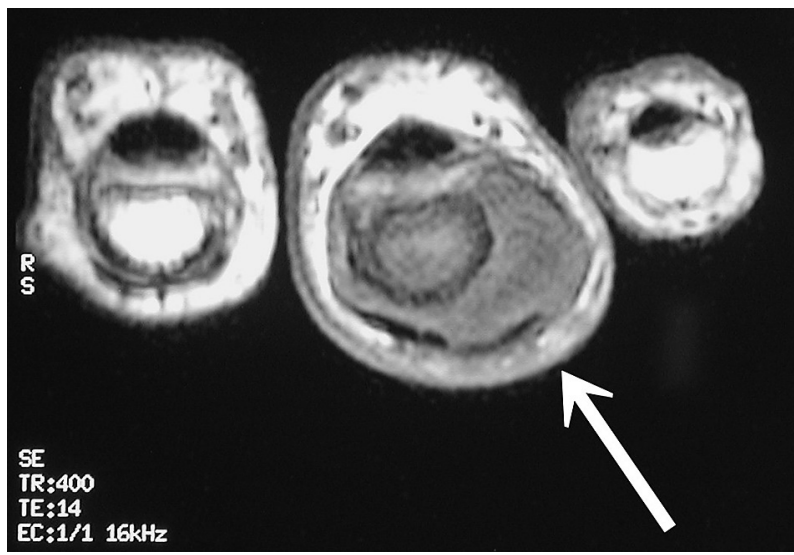

B

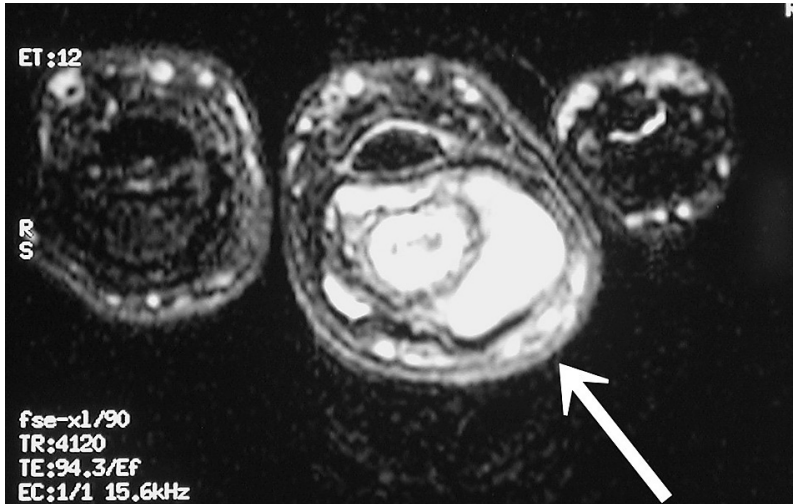

C

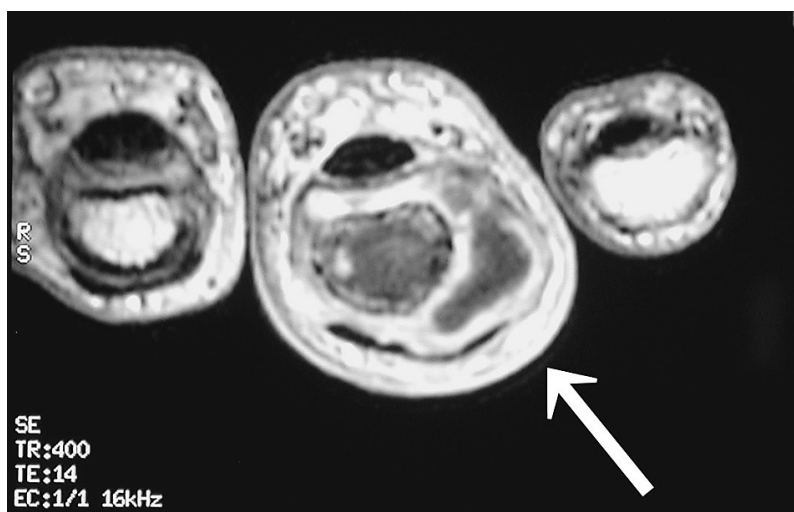

Fig. 4. MRI demonstrating an extraskeletal lesion (arrow) with iso signal intensities on T1 weighted image (A), high signal intensities on T2 weighted image (B) and enhancement at the peripheral area after gadolinium injection (C).
4B and 4C). Chondrosarcoma was radiologically suspected rather than an enchondroma. However, thorough curettage and artificial bone grafting were chosen as treatment based on the old age of the patient and his senile dementia and the strong desire of the patient and his family. Postoperative histological examination revealed that the tumor was composed of star-shaped or polygonal cells with eosinophilic cytoplasm proliferating in the chondromatous matrix with partially myxoid changes. Nuclear irregularity and binucleated cells were observed (Fig. 5a). Permeation of preexisting bone (Fig. 5b) was also present. The

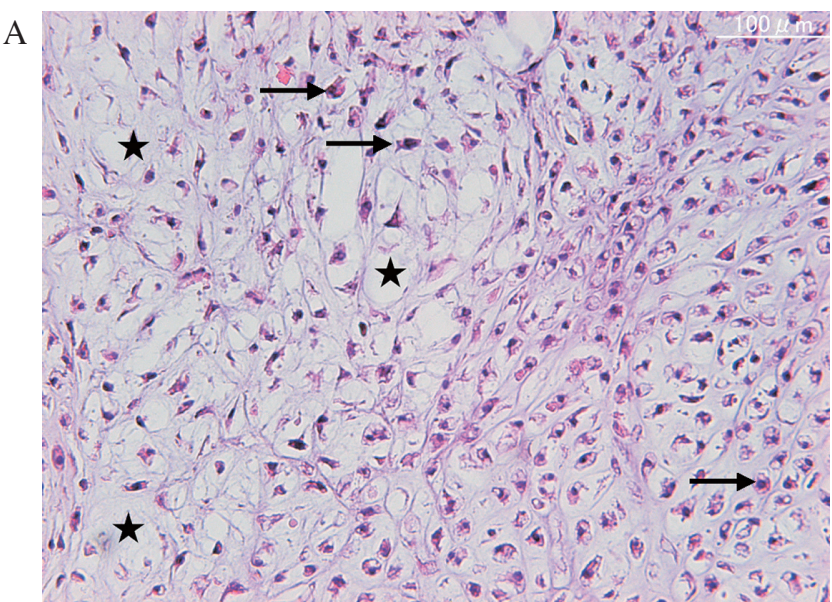

B

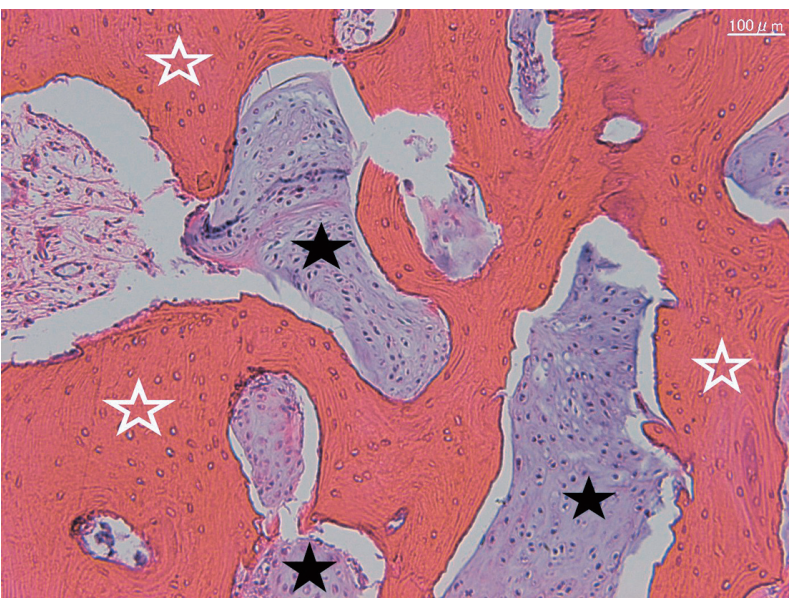

Fig. 5. Microphotograph showing star-shaped or polygonal cells with nuclear irregularity and eosinophilic cytoplasm (arrows) proliferating in the chondromatous matrix with myxoid changes $(\star)(\mathrm{A})$. Permeation of the preexisting bone $(\hbar)$ by the tumor $(\star)$ was present (B). 
tumor was diagnosed as grade 2 chondrosarcoma. Five months after surgery, the tumor recurred rapidly and amputation of the ring finger including the distal part of the 4th metacarpal bone was performed. Postoperative histological examination demonstrated the same pattern observed at the previous surgery. At two years after surgery, the patient was free from recurrence or lung metastasis.

\section{Discussion}

\section{Clinical picture}

Chondrosarcoma of the hands has been sporadically reported. Nigrisoli et al. (1990) in a series of 506 chondrosarcomas found only four cases $(<1 \%)$ in the hand, and Unni (1996) found that only $1.5 \%$ of 635 chondrosarcomas were in the hand. The median age of the patients at the time of diagnosis was over 60 , with a slight female predominance. Occurrence in the hand was more common than in the foot, with the proximal phalanx affected most often (Bovee et al. 1999; Patil et al. 2003). The duration between the first clinical symptoms and first surgery ranged from two months to 30 years (Gohla et al. 2004). In 2003, Patil (2003) reported 23 patients with chondrosarcoma of the bones of the hand. In his series, eleven patients presented with progressive swelling, and $26 \%$ had symptoms for over 10 years. Initial clinical misdiagnosis as ganglion, bursa, gout, rheumatoid arthritis and cyst occurred in five patients. Roberts and Price (1977) stressed that the usual clinical presentation was a progressively painful large tumor, often arising in a dormant lesion near the metacarpo-phalangeal joint. These clinical features correspond well to those of the present case, an 80-year-old man, with swelling and pain of the proximal phalanx of the ring finger for seven years. Usually, enchondroma of the hand rarely causes swelling or pain except in the case of a pathological fracture. Therefore, painful swelling for a long period in the aged is thought to a helpful sign toward making the diagnosis of chondrosarcoma of the hand.

\section{Malignant transformation}

It is well known that some patients with multiple enchondromatosis develop secondary chondrosarcoma, although rarely in the hand (Goto et al. 2003). The form of multiple enchondromatosis with unilateral predominance is termed Ollier's disease. Malignant transformation into chondrosarcoma or osteosarcoma with Ollier's diease has been reported (Miyawaki et al. 1997). Maffucci syndrome is also a rare, congenital disease that is associated with multiple enchondromas. The possibility of malignant transformation including chondrosarcoma is 20 to $100 \%$ (Ramirez-Bollas et al. 2005). In contrast, malignant transformation of solitary enchondroma into chondrosarcoma is extremely rare (Peiper and Zorning 1997; Koak et al. 2000; Müller et al. 2004). Such a change occurred in only two out of 112 patients with enchondroma of the hand (Rieger et al. 2000). Wu et al. (1983) reported a chondrosarcoma of the hand arising from an asymptomatic benign solitary enchondroma of 40 years' duration. Therefore, the possibility of malignant change in enchondromas should be borne in mind (Kuur et al. 1989). Any cartilaginous lesions that are still active or painful after termination of the growth period should be examined thoroughly for the presence of malignant transformation (Miyawaki et al. 1997). In 1975, Culver et al. (1975) reported a case of a chondrosarcoma of the proximal phalanx of the right index finger in a 66-year-old woman that demonstrated histological evidence of malignant transformation of a pre-existent benign solitary enchondroma. In the present case, malignant transformation from enchondroma in the phalanx to chondrosarcoma was less likely because multiple enchondromas were ruled out radiologically and no enchodromatous lesion adjacent to the chondrosarcomatous portion was found histologically.

\section{Radiological diagnosis}

The diagnosis of chondrosarcoma of the hand can be as difficult for the surgeon as for the pathologist. The histological criteria for differentiation between chondrosarcoma and enchondroma are not well defined. Chondrosarcoma of the hand tends to be easily misdiagnosed as enchon- 
droma (Gohla et al. 2004). Distinguishing the two entities is clinically relevant, as chondrosarcomas of the hand, despite their low tendency for metastatic spread, require a prompt and more radical treatment than enchondromas (Gohla et al. 2004). Radiologically, most lesions of chondrosarcomas of the hand show bone expansion, cortical destruction and large soft-tissue extension (Roberts and Price 1977; Ogose et al. 1997; Essadki et al. 2001; Goto et al. 2003; Patil et al. 2003). The present case also had extraskeletal growth of the tumor, which was clearly demonstrated by magnetic resonance imaging (MRI) (Fig. 4). The irregular cortical thickening shown by CT (Fig. 3) in the present case is thought to be another useful sign to arrive at the correct diagnosis of chondrosarcoma of the phalanx because cortical thickening is rarely seen in enchondroma of the hand. Periosteal chondroma, a cartilaginous tumor that arises on the outer surface of a bone beneath the periosteum can be differentiated from chondrosarcoma because of absence of intramedullary extension or cortical thickening in periosteal chondroma (Hatori et al. 1991; Hagiwara et al. 2004)

\section{Histological diagnosis}

Microscopically, enchondroma is hypocellular with few double-nucleated cells without cytologic atypia. There is no permeation of bone. The matrix usually does not show myxoid change. However, enchondromas in the hand tend to show high cellularity, enlargement of nuclei, and many double-nucleated cells. Hence, histological interpretation of cartilaginous lesions of the hand is often difficult, particularly in the differential diagnosis from chondrosarcoma (Ogose et al. 1997). Confusion might arise from the inclusion of bland areas of chondromatous tissue that probably represent the original lesion (Roberts and Price 1977). Culver et al. (1975) stated that careful analysis of the preoperative $\mathrm{x}$-ray for punctate endosteal calcification or cortical expansion and ample histological sampling of the endosteal component of chondrosarcomas arising from within bone may demonstrate a greater incidence of preexistent enchondroma. The clinical behavior and radiographic appearance at surgery are often more reliable indicators of malignancy. Thorough examination is necessary when an older individual presents with a previously quiescent lesion that becomes larger and/or more symptomatic (Cash and Haberman 1988). Ostlere et al. (1991) and Gohla et al. (2004) emphasized the importance of correlating the histological features with the radiological and clinical findings of all bone tumors, especially cartilaginous lesions. Histologically, soft tissue extension and permeation of preexisting bone indicate malignant disease (Ogose et al. 1997). The majority of such cases show high histological grade (grade 2 and 3) with extensive myxoid areas (Bovee et al. 1999; Exner et al. 2003; Patil et al. 2003). The histological features of the removed specimen from the present case well correlated with the radiological and histological findings of chondrosarcoma.

\section{Surgical treatment}

Chondrosarcomas are malignant tumors and need to be treated aggressively with ablative surgery. However, as for chondrosarcoma of the hands, there has been controversy concerning radical treatment. Bovee et al. (1999) stated that the biologic behavior is relatively indolent, although phalangeal chondrosarcoma may have ominous histological features. The potential for systemic disease for chondrosarcomas of the phalanges is probably much lower than in chondrosarcomas of other localizations (Roberts and Price 1977; Pathak et al. 2001; Exner et al. 2003). The low risk of metastases despite the high histological grade indicates that chondrosarcomas of the hand behave differently from chondrosarcomas elsewhere (Bovee et al. 1999; Patil et al. 2003). Bovee et al. (1999) has recently drawn attention to the lower aggressive behavior of chondrosarcomas of the phalanges compared with those of other localizations including the metacarpals. However, conservative treatment is difficult due to the small size of the hand, which allows easy spread of the tumor from compartment to compartment (Essadki et al. 2001). Therefore in cases originally treated with curettage or excision, local recurrence is very high (Roberts and Price 1977; 
Wirbel and Remberger 1999; Essadki et al. 2001; Pathak et al. 2001; Exner et al. 2003; Patil et al. 2003). Wirbel and Remberger (1999) reported a case whose lesion in the first metacarpal bone was radiographically interpreted initially as an enchondroma and treated conventionally by curettage and cancellous autologous bone grafting but later showed recurrence. No recurrence has been reported in case treated by ray resection or amputation of the phalanx. Despite the low metastatic potential of chondrosarcomas of the hand in comparison with other sites, ray resection or digital amputation has been recommended to avoid local recurrence (Cash and Habermann 1988; Hernandez-Vaquero et al. 1991; Patil et al. 2003). Digit-sparing techniques may also be considered rather than ablative procedures (Exner et al. 2003). Bovee et al. (1999) believe that curettage with adequate follow-up should be considered as the treatment of choice if technically feasible, especially in cases in which amputation would lead to a significant loss of hand function. In cases with only local excision, close follow-up is also recommended (Gohla et al. 2004). Mittermayer et al. (2004) stated that intralesional resection is the preferred method of treatment in Grade 1 chondrosarcoma of the hand because of low recurrence rate and no metastasis in his series, allowing the patient to avoid amputation and major loss of function. In the present case, thorough curettage and bone grafting was tried once because of the age ( 80 years old) and senile dementia of the patient and the desire of the patient and his family. But rapid recurrence at five months after curettage and the diagnosis of Grade 2 chondrosarcoma made us decide on ray amputation including the distal portion of the metacarpal bone of the ring finger. This amputation did not significantly interfere with the function of the hand and the patient remained free of disease.

\section{Conclusion}

Chondrosarcoma of the hand is very rare. It behaves as a locally aggressive lesion. In addition to the pathological findings, painful swelling for a long period for the aged, cortical irregular thickening and disruption, and soft tissue extension are thought to be useful signs for the diagnosis of chondrosarcoma of the hand. Wide excision is recommended to avoid local recurrence or metastasis.

\section{References}

Bertoni, F., Bacchini, P. \& Hogendoorn, P.C.W. (2002) Chondrosarcoma. In: Pathology and Genetics of Tumours of Soft Tissue and Bon, IARC Press, Lyon, pp. 247-248.

Bovee, J.V., van der Heul, R.O., Taminiau, A.H. \& Hogendoorn, P.C. (1999) Chondrosarcoma of the phalanx: a locally aggressive lesion with minimal metastatic potential: a report of 35 cases and a review of the literature. Cancer, 86, $1635-1637$.

Cash, S.L. \& Habermann, E.T. (1988) Chondrosarcoma of the small bones of the hand: case report and review of the literature. Orthop. Rev., 17, 365-369.

Culver, J.E., Jr., Sweet, D.E. \& McCue, F.C. (1975) Chondrosarcoma of the hand arising from a pre-existent benign solitary enchondroma. Clin. Orthop. Relat. Res., 113, 128-131.

Essadki, B., Belabidia, B., Fikry, T., Moujtahid, M., Lamine, A., Essadki, O. \& Zryouil, B. (2001) Chondrosarcoma of the hand. Diagnostic and therapeutic discussion (three case reports). Chir. Main., 20, 164-171.

Exner, G.U., Dumont, C.E., Malinin, T.I. \& von Hochstetter, A.R. (2003) Recurrent aggressive chondrosarcoma of the middle phalanx of the index finger: excision and reconstruction with an osteocartilaginous allograft. Arch. Orthop. Trauma Surg., 123, 425-428.

Gohla, T., van Schoonhoven, J., Prommersberger, K.J. \& Lanz, U. (2004) Chondrosarcomas of the hand. Handchir. Mikrochir. Plast. Chir., 36, 328-332.

Goto, T., Motoi, T., Komiya, K., Motoi, N., Okuma, T., Okazaki, H., Takatori, Y., Tange, T. \& Nakamura, K. (2003) Chondrosarcoma of the hand secondary to multiple enchondromatosis; report of two cases. Arch. Orthop. Trauma Surg., 123, 42-47.

Hagiwara, Y., Abe, A., Hatori, M. \& Kokubun, S. (2004) Periosteal chondroma of the fifth toe-A case report. Upsala $J$. Med. Sci., 109, 65-70.

Hatori, M., Ehara, S., Nagaya, S., Ishibashi, K. \& Kokubun, S. (1991) Periosteal chondroma in the great toe. The Foot, 6 148-151.

Hernandez-Vaquero, D., Cima-Suarez, M. \& Garcia-Pravia, C. (1991) Chondrosarcoma of the bones of the hand. Report of two cases. Arch. Orthop. Trauma Surg., 110, 265-268.

Koak, Y.P., Patil, P.S. \& Mackenny, R.P. (2000) Chondrosarcoma of the distal phalanx of a toe. A case report. Acta Orthop. Belg., 66, 286-288.

Kuur, E., Hansen, S.L. \& Lindequist, S. (1989) Treatment of solitary enchondromas in fingers. J. Hand Surg. (Br)., 14, 109-112.

Mittermayer, F., Dominkus, M., Krepler, P., Schwameis, E., Sluga, M., Toma, C., Lang, S., Grampp, S. \& Kotz, R. (2004) Chondrosarcoma of the hand: is a wide surgical resection necessary? Clin. Orthop. Relat Res., 424, 211-215.

Miyawaki, T., Kinoshita, Y. \& Iizuka, T. (1997) A case of Ollier's disease of the hand. Ann. Plast. Surg., 38, 77-80.

Müller, P.E., Dürr, H.R., Nerlich, A., Pellengahr, C., Maier, M. \& Jansson, V. (2004) Malignant transformation of a benign 
enchondroma of the hand to secondary chondrosarcoma with isolated pulmonary metastasis. Acta Chir. Belg., 104, 341-344.

Nigrisoli, M., Ferraro, A., De Cristofaro, R. \& Picci, P. (1990) Chondrosarcoma of the hand and foot. Chir. Organi. Mov., 75, 315-323.

Ogose, A., Unni, K.K., Swee, R.G., May, G.K., Rowland, C.M. \& Sim, F.H. (1997) Chondrosarcoma of small bones of the hands and feet. Cancer, 80, 50-59.

Ostlere, S.J., Gold, R.H., Mirra, J.M. \& Perlman, R.D. (1991) Case report 658: Chondrosarcoma of the proximal phalanx of right fourth finger secondary to multiple hereditary exostoses (MHE). Skeletal Radiol., 20, 145-148.

Pathak, G., Conolly, W.B. \& McCarthy, S.W. (2001) Chondrosarcoma of thumb metacarpal - a case report with literature review. Hand Surg., 6, 81-87.

Patil, S., de Silva, M.V., Crossan, J. \& Reid, R. (2003) Chondrosarcoma of small bones of the hand. J. Hand Surg. (Br)., 28, 602-608.

Peiper, M. \& Zornig, C. (1997) Chondrosarcoma of the thumb arising from a solitary enchondroma. Arch. Orthop.
Trauma Surg., 116, 246-248.

Ramirez-Bollas, J., Padilla-Rosciano, A., Romero-Y, Huesca A., Lavin-Lozano, A.J., Medina-Castro, J.M., Dubon-Garcia, E. \& Turcios-Cadenas, E.R. (2005) Maffucci's syndrome. Case reports and literature review. Cir. Cir., 73, 217-221.

Rieger, H., Neuber, M., Joosten, U., Grunert, J., Brug, E. \& Strobel, M. (2000) Therapy and prognosis of enchondroma of the hand. Chirurg., 71, 1152-1155.

Roberts, P.H. \& Price, C.H. (1977) Chondrosarcoma of the bones of the hand. J. Bone Joint Surg. Br., 59, 213-221.

Unni, K.K. (1996) Chondrosarcoma (primary, secondary, dedifferentiated, and clear cell). In: Dahlin's Bone Tumors. General Aspects and Data on 11,087 Cases. 5th ed., Lippincott-Raven, Philadelphia, pp. 71-108.

Wirbel, R.J. \& Remberger, K. (1999) Conservative surgery for chondrosarcoma of the first metacarpal bone. Acta Orthop. Belg., 65, 226-229.

Wu, K.K., Frost, H.M. \& Guise, E.E. (1983) A chondrosarcoma of the hand arising from an asymptomatic benign solitary enchondroma of 40 years' duration. J. Hand Surg. (Am)., 8, 317-319. 